\title{
O PROFESSOR DE LÍNGUAS, SEUS FALSOS MITOS E OS NOVOS DESAFIOS EM SALA DE AULA
}

\author{
Luciane Kirchhof Ticks \\ luticks@brturbo.com
}

\section{RESUMO}

Este artigo faz uma breve discussão a respeito das dificuldades enfrentadas por professores de línguas em encontrar seu espaço, reconhecer sua identidade, seu papel e o dos seus alunos no contexto de sala de aula. Além disso, propõe um diálogo acerca da dicotomia teoria e prática na construção de uma abordagem pedagógica.

\section{INTRODUÇÃO}

Era uma vez uma professora de língua estrangeira que acabara que retornar de seu curso de mestrado, direto para a sala de aula de um 3o ano do ensino médio. Disciplinada, disposta e, na verdade, cheia de vontade de arregaçar as mangas e trabalhar com aqueles que são o motivo de seus estudos, a razão dos seus dois anos de dedicação no curso de especialização, a professora não via a hora de começar a colocar em prática todos os ensinamentos que aprendera durante sua graduação e mestrado.

Mas qual não foi a sua surpresa quando, nas duas primeiras semanas de aula, começa a ser desvelada, diante de seus olhos, a dura realidade da profissão: a universidade está longe de preparar o professor para o que está por vir e, ao pisarmos na sala de aula, nos damos conta de que muito do que aprendemos na academia não parece ter serventia e de que um longo, desconhecido e novo processo de aprendizagem está só começando.

Nos conta a professora:

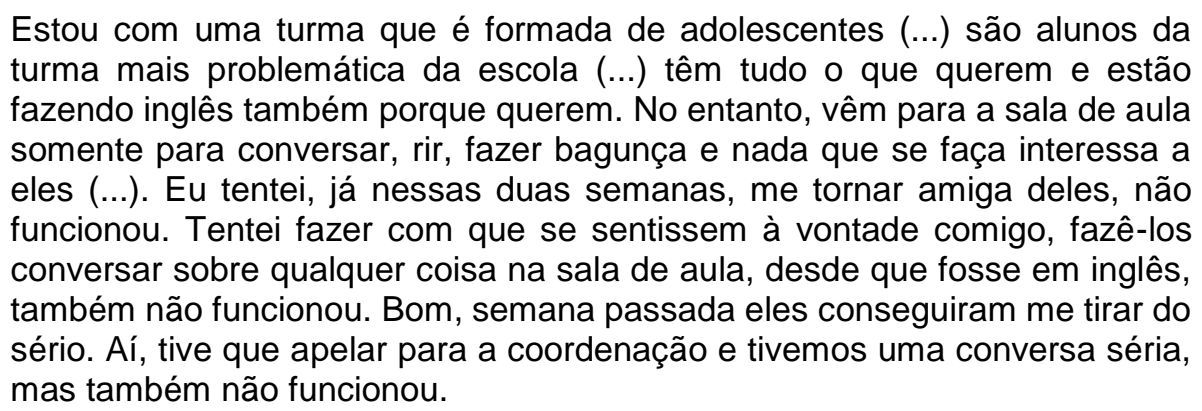


Esta não é uma história da carochinha e está longe de ser um conto de fadas. Mas, mesmo não sendo, quais as possibilidades de ter um final feliz? Sempre pensamos no professor como um ser que nasceu com "habilidades especiais", "instinto aguçado" e "aquela capacidade" de inebriar a platéia sedenta de informação: a encarnação do "Mr. Keating" (professor de literatura do filme Sociedade dos Poetas Mortos), que desejaríamos ardentemente ter tido ao nosso lado durante os anos escolares e no qual, finalmente, nos transformaríamos ao sairmos da faculdade, prontos!.

Ao invés disso, deixamos a academia com o diploma numa mão e um punhado de teorias na outra, que confiamos serem a resposta para todos os problemas que estão por vir no decorrer de nossa profissão. Entretanto, ao nos colocarmos em sala de aula, o primeiro sentimento que temos é o de justamente não conseguirmos enxergar o nosso espaço, a nossa identidade e o nosso papel naquele contexto que nos parecia, antes, tão familiar e que abrigou o nosso processo de aprendizagem por pelo menos uma década, enquanto éramos alunos.

Mas voltando à nossa professora, ela não desistiu lá, na sala da coordenação. Logo depois, ela escreve:

O grande problema deles é que eles não se concentram em nada...é como se pegassem um fio de lã e fossem enrolando... um puxa o outro..e aí vai dando um bolo....e todo mundo começa junto e só param sob pressão....é terrível isso...não sei o que fazer.

\section{OS FALSOS MITOS RECALCADOS NA IDENTIDADE DO PROFESSOR}

Lá se vão dois grandes mitos, dois falsos universais psicológicos (Ratner, 1995: 105) que foram calcificados à imagem, à (falsa) identidade do professor: o de que ele é a personificação do carisma, o nosso "Mr. Keating", de novo, que deixa seus alunos embevecidos com suas palavras, e o do profissional que tem resposta para tudo na sua mágica cartola. Mas, mais daninho do que o mito de ter resposta para tudo é o de que o professor deve tê-las. Que espécie de professor é esse ou essa se não as tem? Da espécie que deve começar a questionar tais conceitos, se despir de todos eles, se preciso, e começar de onde for preciso: que tal do começo? Mas, antes disso, talvez seja interessante discutir outros falsos universais psicológicos que nos fazem ser quem somos e, muitas vezes, nos impedem de serem quem gostaríamos. 
Talvez o mais arraigado, sutil e difícil de ser reconhecimento seja o mito do senso comum. Ele está em todos os lugares e alcança a todos, sem exceção, uma vez que somos seres sociais, constituídos dentro de um contexto sócio-histórico (Bakhtin, 1990). Essa natureza social, ideológica e inconsciente do sujeito, salientada por Bakhtin, nos ajuda a entender como o chamado senso comum é incorporado à nossa cultura, aos nossos valores, sem que muitas vezes o percebamos lá.

Nesse sentido, o senso comum passa a ser o certo, passa a ser lei e, portanto, inquestionável. De volta à identidade do professor, atualmente tão desgastada, podemos nomear uma série de outros falsos universais, agora negativos, que a ela foram incorporados e fazem parte do senso comum. Tais (pré)conceitos tentam explicar porque temos enfrentado dificuldades para lidar com nossos alunos em sala de aula. Vejam só: o professor só quer saber de lutar por salário, se acomodou, não está interessado na aprendizagem.

De volta à nossa professora de línguas, ela nos confessa:

Esta noite nem dormi pensando como agir (...) Pensei (...) em descobrir algumas técnicas de relaxamento... exercícios de concentração... games... atividades que fizessem eles gastarem energia.... atividades dentro e fora da escola (...)

Bem, dizer que estamos preocupados apenas com salários, que nos acomodamos... Será que somos todos assim? Será que não encontramos alguns ou até um bom número de professores recém-formados, maduros e próximos da aposentadoria perdendo o sono, preocupados e angustiados com o seu contexto de trabalho? De que vale o maniqueísmo - somos todos bons ou todos péssimos educadores nessas horas? De nada. Acredito que haja, sim, uma boa parcela de profissionais interessados, preocupados e dispostos a pensar sobre o seu contexto de trabalho. $E$ é nessa parcela que devemos investir, nela que devemos cultivar um pensar crítico para que este crie raízes, dê bons frutos e alimente outros tantos necessitados.

É claro que o papel mais difícil e trabalhoso recai sobre os ombros do professor, que precisa lutar contra todos esses falsos mitos para encontrar a sua verdadeira identidade. Ele recorrentemente tem se deixado levar por eles. Quantas e quantas vezes ouvimos profissionais da área da educação se esconderem através desses mesmos falsos universais para justificar a sua dificuldade em agir? Podemos identificar pelo menos três estágios de inércia. 
O primeiro é o da negação: "não, não, não, as minhas turmas são ótimas, não tenho problema com elas, são superobedientes". Negar o problema resolve ou apenas amortece e camufla um comportamento que pode reaparecer a qualquer momento, em qualquer outro lugar? Nesse caso, o professor nega o outro, seus alunos. Segundo Maturana (2001: 38), a negação se dá porque o outro está em um domínio da realidade diferente da do professor, que é igualmente válido, mas que não o agrada.

O segundo é o da sobrecarga de trabalho: "você nem imagina, mas estou com 14 turmas e quase 400 alunos. Não tenho tempo nem para pensar, de tanto trabalho!". Assim, o professor se isenta da responsabilidade de agir sobre o seu contexto, tendo em vista que está carregando o mundo nas costas e não há espaço para mais nada. Pensar se tornou um artigo de luxo e o professor admite não ser responsável pelas coisas que acontecem com ele.

Para Maturana (Id.: 36), neste caminho explicativo, há uma realidade que é independente daquela do observador. O observador, no caso o professor, tem acesso a ela e a mesma dá subsídios para que ele elabore sua explicação, que nada mais é do que uma petição de obediência. "Todos vocês têm que fazer o que eu digo, porque a validade do que digo não depende de mim — é própria daquilo que eu indico" (Id.: Ibidem).

O terceiro é o grupo dos que já tentaram de tudo e nada funcionou. Nesse caso, estão os professores que se sentem derrotados pelo contexto. Lançaram mão de tudo que aprenderem e se sentem, inclusive, traídos pela universidade, que, em momento algum, os alertou de que isso aconteceria ou os preparou para tal fim. Esse talvez seja o mais triste deles, pois parecem ter perdido tudo no processo: sonhos, esperanças e, inclusive, o bom humor. Normalmente, lançam mão do poder que o cargo thes confere para dar conta da sala de aula, utilizando sua autoridade como professor para "disciplinar recorrentes problemas de comportamento".

Assim, o mais complicado é o processo de rompimento com esses mitos para nos colocarmos em condições de repensarmos o nosso contexto. Saímos da faculdade com uma série de abordagens metodológicas na "ponta da língua", nas quais depositamos nossas esperanças e expectativas de solução de todo e qualquer problema. No entanto, ao chegarmos à sala de aula, nos vemos obrigados a repensálas e, em alguns casos, colocá-las de lado. 


\section{POR UM PENSAR CRÍTICO}

Kumaravadivelu (1994: 29) propõe uma análise crítica acerca da relação de dependência existente entre o ensino de línguas e o método. E esse não é um questionamento solitário, pois, a partir dos anos 90, outros lingüistas (Moita Lopes, 1996; Rigg, 1991 e Prabhu, 1990) começam a questionar a necessidade de um ensino pautado por metodologias específicas. Tais idéias discutem a adoção de uma postura pedagógica alternativa ao método, ao invés de um método alternativo (Kumaravadivelu, 1994: 29).

Kumaravadivelu (2001: 537) entende que podemos avançar na medida em que trabalhamos por um sistema tridimensional integrado por três parâmetros: a) da particularidade, caracterizado por uma educação voltada para o contexto onde está inserida, com um verdadeiro entendimento das particularidades socioculturais, lingüísticas e políticas; b) da "praticalidade", ou seja, a ruptura da divisão entre teóricos e usuários dos métodos, através da instrumentalização dos professores para que desenvolvam sua própria prática teórica e c) da possibilidade, que valorizaria a consciência sóciopolítica dos participantes para ajudá-los na busca da formação de suas identidades e da transformação social .

No primeiro elemento, o da particularidade, encontra-se o pressuposto de que qualquer pedagogia precisa ser sensível ao meio onde está inserida, deve reconhecêlo e inseri-lo como parte integrante do processo pedagógico. Segundo Kumaravadivelu, a particularidade é um objetivo e um processo, pois se trabalha por e através dela. Representa, em última instância, uma consciência crítica das exigências locais. E, dialeticamente, são essas exigências que desencadeiam a realização de uma pedagogia da particularidade (2001: 539).

Por outro lado, Prabhu (1990: 162) alerta para a importância de identificarmos adequadamente que fator (ou fatores) é mais relevante entre tantas variáveis relativas ao processo pedagógico centrado no contexto. Ao levarmos este em consideração, devemos tratar de inúmeros elementos relativos à situação social (meio ambiente, atitudes culturais e lingüísticas, fatores ideológicos e econômicos), à organização educacional (objetivos instrucionais, eficiência administrativa, tamanho da sala de aula etc), aos professores (treinamento, autonomia, habilidades etc) e aos alunos (idade, 
aspirações, experiências prévias etc). A lista parece não ter fim e Prabhu ressalta que quanto mais elaborada for a análise contextual, maior será o número de critérios que deverão ser atendidos pelos procedimentos e conteúdo instrucional e, menores, portanto, as chances de atendê-los (Id: 164).

O segundo elemento valorizado por Kumaravadivelu (2001: 541), a pedagogia da "praticalidade", vai além da vivência diária da sala de aula. Ela resulta do encontro da teoria e da prática e procura superar algumas deficiências inerentes à dicotomia "teoria x prática", encorajando e permitindo que professores teorizem sobre a sua prática e possam colocar essa produção em sala de aula.

A lingüística aplicada tradicional vem construindo metodologias de pesquisa com o objetivo de solucionar problemas práticos do dia-a-dia da sala de aula. Essa postura metodológica, que Moita Lopes (1996: 83) chama de investigação teóricoespeculativa, parte da observação da realidade pelo pesquisador, que faz a sua teorização e, posteriormente, retorna à sala de aula para aplicá-la. Esse procedimento deveria abrandar a relação dicotômica entre teoria e prática, pois o lingüista aplicado ensinaria ao professor como proceder em sala de aula, a partir de seus ensinamentos teóricos. No entanto, Coracini (1998: 3) chama a atenção para o fato de que a passagem da teoria para a prática não se dá de forma "natural" e "direta", uma vez que os sujeitos - professor e aluno - são marcados por sua historicidade e pelo seu inconsciente e, freqüentemente, deparam-se com a impossibilidade de controlar, ou mesmo modificar sua realidade.

Nesse sentido, a lingüística aplicada tradicional tem levado em consideração apenas a concepção do sujeito consciente e racional, que integra novos conceitos, informações e valores aos previamente adquiridos e modifica sua estrutura cognitiva (Ausubel, 1978). Essa ênfase na cognição e inteligência, lembra Coracini (1988: 6), pressupõe a idéia do sujeito cartesiano e deixa de lado a natureza social e ideológica (inconsciente) do sujeito (Bakhtin, 1990). "Como decorrência do sujeito ideal consciente, os estudos cognitivistas vêm reforçar a perspectiva simplista das relações diretas, não problematizadas, entre teoria e prática..." (Coracini, 1988: 6). E, nesse sentido, Pennycook "dialoga" com Coracini: "...this version of free individuals misses 
an understanding of how society, culture, and ideology makes us anything but free" 1 (2001: 119).

Moita Lopes (1996: 89), no entanto, entende que devemos ter um olhar diferente em termos de pesquisa investigativa. Para ele, a grande tendência dos estudos aplicados ao contexto de sala de aula deve remodelar o papel do professor, que deixa de ser apenas consumidor ou cliente de pesquisas desenvolvidas externamente para assumir a postura do próprio pesquisador (Id.: ibidem). Por sua vez, Celani (1997: 159-60) argumenta que devemos pensar o ensino e a pesquisa de línguas voltados para a realidade do aluno brasileiro, deixando de lado "modelos e modismos" produzidos em outros lugares e refletir sobre o nosso contexto. A autora destaca o papel da língua estrangeira na construção da cidadania e como parte integrante da formação global do indivíduo.

A pedagogia da possibilidade, reeditada por Kumaravadivelu (2001), trata justamente dessa construção de cidadãos através da educação, resgatando as idéias de Paulo Freire. Entre seus inúmeros simpatizantes, Benesch (2001) parte do princípio que qualquer pedagogia implica relações de poder e dominação e pode ser usada para sustentar desigualdades sociais. O reconhecimento e o desmascaramento dessas desigualdades fortalece, nos participantes (alunos e professores), a necessidade de desenvolvimento de teorias, formas de conhecimento e práticas sociais que estejam integradas às experiências trazidas por esses mesmos membros (Freire, 1999: 4445).

Essa abordagem crítica da linguagem quer explicar o discurso da sociedade e não simplesmente descrevê-lo. Isso porque a mera descrição garante uma visão da linguagem apenas enquanto produto, como se se tratasse de uma escolha pessoal e não de determinação social (Lancaster \& Taylor, 1992: 256-57). No entanto, a linguagem também deve ser vista enquanto processo, pois implica convenções e práticas marcadas por relações de poder e processos ideológicos que moldam a sociedade, ao mesmo tempo em que são moldadas por ela (Fairclough, 1992: 8).

A partir desse paradigma de criticidade, alunos e professores podem se tornar coconstrutores do seu processo de aprendizagem. Fairclough (1992: 224) ressalta, no

\footnotetext{
${ }^{1}$ Essa versão de indivíduos livres não leva em conta que a sociedade, a cultura e a ideologia nos faz tudo, menos livres.
} 
entanto, que este é ainda um ponto delicado, pois mesmo nos modismos das abordagens centradas no aprendiz (learner-centred approaches), quando se parte para a discussão do "o quê" será aprendido e do "como" isso ocorrerá, os alunos têm pouco ou nenhum poder de escolha.

Além disso, as experiências trazidas pelos participantes não estão relacionadas exclusivamente às referências de ensino/aprendizagem que acumularam em sua vivência, mas também ao ambiente sócio-político e econômico no qual foram criados. Pennycook (1999: 340) chega a sugerir que tomar uma atitude crítica no ensino de uma segunda língua envolve mudanças profundas, muito mais do que simplesmente inserir um "elemento crítico" no currículo.

.... more plausible way forward is through a critical engagement with people's wishes, desires (grifo adicionado), and histories, that is, a way of thinking that pushes one constantly to question rather than to pontificate. ${ }^{2}$ (Id.: 343 ).

Assim, um ensino crítico deve transformar a sala de aula no microcosmo de um mundo cultural e social maior. Esse microcosmo não estaria apenas refletindo, mas reproduzindo e mudando o mundo exterior (Pennycook, 1999: 338). Benesch (1999: 578) acrescenta, ainda, que, para ensinar a pensar criticamente, o professor deve encontrar um equilíbrio entre valorizar as contribuições dos alunos, ao mesmo tempo em que sutilmente os desafia. Assim, precisamos dar um passo para traz, respirar fundo e começar a ouvir novamente os nossos os alunos; sentir e perceber suas necessidades, suas angústias e anseios e, principalmente conhecer suas histórias.

O ponto de equilíbrio pode estar não no abandono de uma proposta, mas num esforço de tentar retirar dela aqueles elementos que podem enriquecer o trabalho em sala de aula, nunca deixando de lado seu caráter ideológico: "ideologies inform and even determine methodologies of language teaching"3 (McCarthy \& Carter, 1994: 38).

Essa insatisfação, em relação aos métodos, está ligada ao fato de que, muitas vezes, eles não conseguem acomodar procedimentos de ensino que consigam dar conta de um sistema tão complexo, como é a linguagem. Diana Larsen-Freeman (1997) discute os conceitos de caos e complexidade utilizados pelas ciências exatas no estudo de

\footnotetext{
2 ...um modo mais plausível se dá através de um envolvimento crítico com os desejos, necessidades e histórias das pessoas, ou seja, uma forma de pensar que as coloque em um processo constante de questionamento ao invés da pontificação.

${ }^{3}$ ideologias informam e até mesmo determinam metodologias de ensino da linguagem.
} 
sistemas dinâmicos não lineares para tratar da linguagem e de aquisição de segunda língua.

Segundo ela, a linguagem também pode ser considerada um sistema dinâmico e não linear, pois atende aos seus critérios de complexidade, ou seja, é composta por subsistemas interdependentes - fonologia, morfologia, léxico, sintaxe, semântica e pragmática (Id.: 149). Assim, qualquer interferência em um de seus subsistemas resulta em alterações nos outros. Da mesma forma que a descrição de uma de suas partes não garante uma descrição da linguagem como um todo. "If language is as complex as it is, it is not likely we will find a single process (grifo adicionado) to account for all the complexity"4 (Id.: 154).

É claro que, para darmos conta dessa complexidade, enquanto professores, precisamos nos instrumentalizar. Mas o que isso quer dizer? Não é simplesmente fazer cursos de aperfeiçoamento nos quais irá participar passivamente, recebendo toneladas de informações sobre esse ou aquele método. Coracini (1998) analisa, com propriedade, trabalhos que tentam perceber em que medida se dá a transformação da prática do professor que participa de cursos de atualização comprometidos a refletir sobre metodologia. Tais trabalhos alimentam a expectativa de que, após alguns anos de encontros e discussões, os professores teriam "plenas condições" de renovar sua prática.

No entanto, para surpresa dos pesquisadores, essa "renovação" nem sempre acontece. A autora entende que em nenhum momento da análise desses trabalhos se considerou o fato de que os sujeitos nem sempre são o que "querem ser" (conscientemente), mas "se constituem historicamente numa dada formação discursiva (heterogênea) por natureza, que exerce papel preponderante no seu dizer e no seu fazer (ao mesmo tempo em que é por eles constituída)" (Coracini, 1998: 6).

Ao reconhecer essa relação dialética entre o social e o individual, Gallimore e Tharp (1996) apresentam uma proposta interessante de instrumentalização, baseada na teoria vygotskiana sobre a Zona de Desenvolvimento Proximal (ZDP). Segundo Vygotsky (1998: 75-6), o desenvolvimento de qualquer capacidade individual de

\footnotetext{
${ }^{4}$ Se a linguagem é, assim, tão complexa, é improvável que encontremos um processo único (singular) que de conta de tal complexidade.
} 
desempenho representa um relacionamento mutável entre a regulação social e a autoregulação.

A partir de Vygotsky, podemos dizer, então, que todos nós, professores ou alunos, estamos sempre retornando ao estágio inicial da ZDP, no qual necessitamos do outro, da regulação social, quando nos aventuramos a aprender algo novo. Às vezes, a autoregulação não é suficiente para restabelecer a capacidade de desempenho. Assim, faz-se necessário um retorno adicional que recupere a regulação externa (Gallimore \& Tharp, 1996: 182). "O objetivo é refazer o caminho do desempenho assistido à autoregulação para novamente sair da ZDP por meio de uma nova automatização" (Id.: ibidem).

Dessa forma, os autores entendem que essa teoria de ensino demonstra a necessidade de dar assistência ao desempenho do aluno para que esse avance no domínio de sucessivas habilidades dentro da ZDP. Gallimore \& Tharp (1996: 182) questionam, então, como podemos ter tão pouco ensino dessa natureza na escola. Para eles, a resposta está no fato de que os próprios professores não desenvolveram sua capacidade de prestar assistência ao desempenho de seus alunos, assim como não têm consciência do desenvolvimento de seu próprio desempenho (Id.: ibidem).

Isso acontece porque a escola, ao invés de dar assistência ao desempenho, limita-se a dirigir e avaliar: ensino através da memorização. Desse modo, os referidos autores propõem um modelo de ensino alternativo, no qual o diretor dá assistência ao coordenador, que dá assistência ao professor, que dá assistência ao aluno (Id.: 183). Giroux (1997: 162) avalia incisivamente o caráter político da escola, pois. “...são lugares que representam formas de conhecimento, práticas de linguagem, relações e valores sociais que são seleções e exclusões (grifo adicionado) particulares da cultura mais ampla". Isso significa dizer que a escola legitima valores que convêm à classe dominante e dificilmente assume uma postura de neutralidade dentro da sociedade onde está inserida.

\section{CONSIDERAÇÕES FINAIS}

No longo e árduo caminho de reescritura e reconstrução de sua identidade, o professor precisa dar o primeiro passo em direção a um entendimento de si enquanto 
sujeito do seu processo de ensino/aprendizagem. Este é o conceito de professores como intelectuais, salientado por Giroux (1997: 161), ou do estudo crítico da linguagem de Fairclough (1992: 7). Para estes autores, a "instrumentalização" do professor deve passar, necessariamente, pela sua experiência e vivência aprendemos a fazer, fazendo (Freire, 2001: 134-35).

Mas essa instrumentalização não significa dizer que ele deva aprender apenas a usar habilidades específicas de ensino da língua-alvo, mas terá que trabalhar também sua consciência crítica (Fairclough, 1992: 6). O professor precisa, portanto, ver-se e ser visto a partir dos interesses políticos e ideológicos que embasam seu discurso e dos valores e relações sociais que legitimam seu programa de ensino. Desse modo, pode produzir sua prática teórica, observando criticamente as muitas alternativas metodológicas disponíveis e selecionando o que é relevante, a partir da realidade onde está inserido, e através do diálogo permanentemente realizado com alunos e colegas de trabalho.

\section{BIBLIOGRAFIA}

AUSUBEL, D. F. (1978). Cognitive factors in learning. New York: Holt. Hinehart and Winston, Inc.

BAKHTIN, M. Paulo: Hucitec. (1990). Marxismo e filosofia da linguagem. 5 ed. São

BENESCH, S. (2001). Critical English for academic purposes: theory, politics, and practice. Mahwah, NJ: Earlbaum. 33(3): $573-95$. (1999). Thinking critically, thinking dialogically. TESOL Quarterly,

CELANI, M. A. A. (1997). Ensino de línguas estrangeiras: olhando para o futuro. In: M. A. A. CELANI (Org.). Ensino de Segunda língua: redescobrindo as origens. São Paulo: EDUC, p. 147-161.

CORACINI, M. J. R. (1998). A teoria e a pratica: a questão da diferença no discurso sobre a da sala de aula. Delta, 14 (1). Disponível em:

http:.../scielo.php?script=sci_arttext\&pid=S0102-

44501998000100003\&lng=pt\&nrm=is. Acesso em: 6 mar. 2002.

FAIRCLOUGH, N. (1992). Critical language awareness. London: Longman.

FREIRE, P. (1999). Educação como prática da liberdade. Rio de Janeiro: Paz e Terra. 
GALLIMORE, R. \& R. THARP. (1996). O pensamento educativo na sociedade: ensino, escolarização e discurso escrito. In: L. C. MOLL (Org.). Vygotsky e a educação: implicações pedagógicas da psicologia sócio-histórica. Porto Alegre: Artes Médicas, p. 171-99.

GIROUX, H. A. (1997). Os professores como intelectuais: rumo a uma pedagogia crítica da aprendizagem. Porto Alegre: Artes Médicas.

KUMARAVADIVELU, B. (2001). Toward a postmethod pedagogy. TESOL Quarterly, 35(4): 537-60.

(1994). The postmethod condition: (e)merging strategies for second/foreign language teaching. TESOL Quarterly, 28 (1): 27-48.

LANCASTER, L. \& R. TAYLOR. (1992). Critical approaches to language learning and pedagogy: a case study. In: N. FAIRCLOUGH (Org.), Critical language awareness. London: Longman, p. 256-84.

LARSEN-FREEMAN, D. (1997). Chaos/complexity science and second language aquisition. Applied Linguistics, 18 (2): 141-65.

MACCARTHY, M. \& R. CARTER. (1994). Language as discourse: perspectives for language teaching. London: Longman.

MATURANA, H. (2001). Cognição, ciência e vida cotidiana. Belo Horizonte: Editora da UFMG.

MOITA LOPES, L. P. (1996). Oficina de lingüística aplicada: a natureza social e educacional dos processos de ensino/aprendizagem de línguas. São Paulo: Mercado de Letras.

PENNYCOOK, A. (2001). Critical applied linguistics: a critical introduction. Mahwah, NJ: Lawrence Earlbaum.

(1999). Introduction: critical approaches to TESOL. TESOL Quarterly, 33 (3): 329-48.

PRABHU, N.S. (1990) There is no best method - Why? TESOL Quarterly, 24(2): 161-76.

RATNER, C. (1995). A psicologia sócio-histórica de Vygotsky. Aplicações contemporâneas. Porto Alegre: Artes Médicas.

RIGG, P. (1991). Whole language in TESOL. TESOL Quarterly, 25 (3): 521-42.

VYGOTSKY, L.S. (1998). A formação social da mente. 6 ed. São Paulo: Martins Fontes. 